\title{
Immunomagnetic microbeads for screening with flow cytometry and identification with nano-liquid chromatography mass spectrometry of ochratoxins in wheat and cereal
}

\author{
Payam Aqai • Jeroen Peters • Arjen Gerssen • \\ Willem Haasnoot • Michel W. F. Nielen
}

Received: 11 February 2011 /Revised: 29 March 2011 / Accepted: 30 March 2011 / Published online: 19 April 2011

(C) The Author(s) 2011. This article is published with open access at Springerlink.com

\begin{abstract}
Multi-analyte binding assays for rapid screening of food contaminants require mass spectrometric identification of compound(s) in suspect samples. An optimal combination is obtained when the same bioreagents are used in both methods; moreover, miniaturisation is important because of the high costs of bioreagents. A concept is demonstrated using superparamagnetic microbeads coated with monoclonal antibodies (Mabs) in a novel direct inhibition flow cytometric immunoassay (FCIA) plus immunoaffinity isolation prior to identification by nanoliquid chromatography-quadrupole time-of-flight-mass spectrometry (nano-LC-Q-ToF-MS). As a model system, the mycotoxin ochratoxin A (OTA) and cross-reacting mycotoxin analogues were analysed in wheat and cereal samples, after a simple extraction, using the FCIA with antiOTA Mabs. The limit of detection for OTA was $0.15 \mathrm{ng} / \mathrm{g}$, which is far below the lowest maximum level of $3 \mathrm{ng} / \mathrm{g}$ established by the European Union. In the immunomagnetic isolation method, a 350-times-higher amount of beads was used to trap ochratoxins from sample extracts. Following a wash step, bound ochratoxins were dissociated from the Mabs using a small volume of acidified acetonitrile/water $(2 / 8 v / v)$ prior to separation plus identification with nano-LC-Q-ToF-MS. In screened suspect naturally contaminated samples, OTA and its non-chlorinated analogue ochratoxin B were successfully
\end{abstract}

\footnotetext{
P. Aqai $(\bowtie) \cdot J$. Peters $\cdot$ A. Gerssen $\cdot$ W. Haasnoot

M. W. F. Nielen

RIKILT - Institute of Food Safety, Wageningen UR,

Akkermaalsbos 2, P.O. Box 230, 6700 AE Wageningen,

The Netherlands

e-mail: payam.aqai@wur.nl

M. W. F. Nielen

Laboratory of Organic Chemistry, Wageningen University, Dreijenplein 8,

6703 HB Wageningen, The Netherlands
}

identified by full scan accurate mass spectrometry as a proof of concept for identification of unknown but crossreacting emerging mycotoxins. Due to the miniaturisation and bioaffinity isolation, this concept might be applicable for the use of other and more expensive bioreagents such as transport proteins and receptors for screening and identification of known and unknown (or masked) emerging food contaminants.

Keywords Flow cytometry · Immunoassay · Magnetic microbeads $\cdot$ Mycotoxins $\cdot$ Cereal $\cdot$ Mass spectrometry . Nano-LC

\section{Introduction}

For the rapid detection of food contaminants, such as mycotoxins, many rapid immunoassays have been developed [1-7]. However, such immunoassays are considered as screening assays due to the risk of false non-compliant results and subsequent confirmation with instruments such as liquid chromatography (LC) combined with mass spectrometry (MS) is compulsory [8]. Screening assays with multi-analyte reagents (group-specific antibodies [9], transport proteins [10], or receptors [11]) are of particular interest since they might pinpoint the occurrence of emerging yet unidentified food contaminants and the subsequent MS identification of the interacting compound (s) is essential. In an ideal situation, to avoid different sample preparations with different selectivities, the screening should be as close as possible to the MS confirmation or identification of unknowns, which could be achieved by using identical bioreagents in both methods. Moreover, miniaturisation is important because of the high costs of bioreagents in general. 
Superparamagnetic carboxylated polystyrene microbeads (MagPlex ${ }^{\mathrm{TM}}(6.5 \mu \mathrm{m}$ diameter beads) $)$ might be used in a multiplex flow cytometric immunoassay (FCIA) for screening several mycotoxins including ochratoxin A (OTA). Superparamagnetic means that the beads can easily be magnetised when an external magnetic field is applied and redispersed immediately when the magnet is removed, which enhances both ease-of-use and automation capabilities [12]. These beads are internally dyed with a red and an infrared fluorophore and by varying the ratio of the two fluorophores, up to 80 different colour-coded bead sets can be distinguished (MultiAnalyte Profiling $\left(\mathrm{xMAP}^{\circledR}\right)$ technology). Each bead set can be covalently coupled, via its carboxylated surface modification, to a different biological probe such as antibodies or other (bio) molecules. In combination with a special flow cytometer (Luminex ${ }^{\circledR}$ ), it is possible to simultaneously measure up to 80 different biomolecular interactions in a single well [13]. Other distinct advantages are high-throughput capability, versatility, accuracy and reproducibility [14]. Multiplex FCIAs were described for the screening of plant proteins, which might be used as adulterants in milk powders [15], pathogens [16], mycotoxins [17], sulfonamides in milk [9] and polycyclic aromatic hydrocarbons in fish [18]. However, all of these are indirect inhibition FCIAs and most of them use non-magnetic beads (MicroPlex ${ }^{\circledR}$ ) coated with antigens and fluorescent labelled (secondary) antibodies for detection.

OTA is a mycotoxin which has carcinogenic, nephrotoxic and teratogenic properties and is produced by Aspergillus and Penicillium fungi [19]. The Aspergillus fungus also produces OTA analogues such as the nonchlorinated ochratoxin B (OTB), ochratoxin $\alpha(\mathrm{OT} \alpha)$, ochratoxin $\beta$ (OT $\beta$ ) and ochratoxin C (OTC; Fig. 1). Most analogues are reported less toxic than OTA but OTC is considered as toxic as OTA since it is converted into OTA after metabolism [19]. All analogues are produced approximately ten times less by the Aspergillus fungus [20]. Regardless of the natural occurrence and toxicity of OTB, OT $\alpha$, OT $\beta$, and OTC, the majority of existing methods are focussed on OTA only. OTA is widely found in cereals, wine, coffee, beer, nuts, dried fruits, and meat products [21]. Cereal and cereal products are the main sources of EU consumer exposure to OTA [22]. The maximum levels (ML) established by the EU for OTA in food [23] vary between 0.5 and $10 \mathrm{ng} / \mathrm{g}$. The ML in cereal and cereal products is $5 \mathrm{ng} / \mathrm{g}$ and if the cereal is meant for direct human consumption, the ML is $3 \mathrm{ng} / \mathrm{g}$. The lowest OTA ML of $0.5 \mathrm{ng} / \mathrm{g}$ is established for baby food. Guidance values in feed vary between 50 and $250 \mathrm{ng} / \mathrm{g}$ and for OTA in cereal or cereal products used as feed material $250 \mathrm{ng} / \mathrm{g}$ is applied [24]. For the detection of OTA and other mycotoxins, immunoaffinity chromatography (IAC) is a common tool for the specific isolation from sample materials prior to HPLC or LC-MS analysis [6, 25, 26]. However, such IAC columns are voluminous and use high amounts of carrier material with a high risk of non-specific binding. They consume lots of antibodies and require large volumes of chemicals for extraction and elution, with extra time for evaporation, and sometimes filtration of the sample extracts to remove matrix particles. Several of these disadvantages are overcome by the miniaturised immunoextraction method for OTA as described by Faure et al. [4] using in situ polymerisation of a monolithic stationary phase with highly reactive epoxy groups for protein coupling. However, the crucial polymerisation step requires both time $(>10 \mathrm{~h})$ and expertise and the antibody immobilisation is also time-consuming ( $>18 \mathrm{~h})$. Applications of bioaffinity superparamagnetic beads are described for extracting and pre-concentrating proteins, lipopolysaccharides [27, 28], hormones and drugs [29] and in proteomic profiling [30]. They can operate in small volumes and simplify sample preparation procedures. MagPlex ${ }^{\mathrm{TM}}$ superparamagnetic microbeads coated with antibodies have the extra advantage that they can also be used in the flow cytrometric screening assay. Covalent coupling of these beads with proteins (e.g. antibodies) is not laborious $(<4 \mathrm{~h})$.

In the present research, the concept of using identical bioreagents in both screening and identification methods was investigated by using superparamagnetic microbeads (beads) in a direct inhibition FCIA for the screening of OTA, a relevant model food contaminant, and for the immunomagnetic isolation prior to identification by nanoLC-Q-ToF-MS. This identification technique was used because of its high sensitivity, small injection volumes, ultralow flow rates, resulting in the low consumption of hazardous chemicals, and the option to operate in full scan accurate mass mode for the identification of unknown compounds based on elemental composition calculated thereof. The optimisation experiments were performed with high-pressure liquid chromatography-triple-quadrupole mass spectrometry (LC-QqQ-MS) due to its high sensitivity and availability. In this research, one set of the paramagnetic beads was coated with monoclonal antibodies (Mabs) against OTA and, for the detection, OTA was coupled to the fluorescent protein R-Phycoerythrin (R-PE) according to a procedure described by Kawamura et al. [31]. As a model, we focused on the development and application of a rapid screening assay for OTA in wheat and cereal for human consumption, which can easily be extended to other mycotoxins in the future. The same Mab-coated beads, but in different amounts, were used for the specific miniaturised immunoaffinity isolation of OTA and cross-reacting analogues, prior to the identification with nano-LC-Q-ToF-MS. 
Fig. 1 Molecular structures, elemental compositions and theoretical exact masses of $\mathbf{A}$ OTA, B OTB, C OTC, D OT $\alpha$ and $\mathbf{E}$ OT $\beta$<smiles>CCOC(=O)O[Mg]O[Mg]</smiles>

B<smiles>CC1Cc2ccc(C(=O)NC(Cc3ccccc3)C(=O)O)c(O)c2C(=O)O1</smiles>
$\mathrm{C}_{20} \mathrm{H}_{19} \mathrm{NO}_{6}, 369.1212$ Dalton

$\mathrm{D}$<smiles>CCOC(=O)C(Cc1ccccc1)NC(=O)c1cc(Cl)c2c(c1O)C(=O)OC(C)C2</smiles>
$\mathrm{C}_{22} \mathrm{H}_{22} \mathrm{ClNO}_{6}, 431.1136$ Dalton $\mathrm{C}_{11} \mathrm{H}_{9} \mathrm{ClO}_{5}, 256.0139$ Dalton

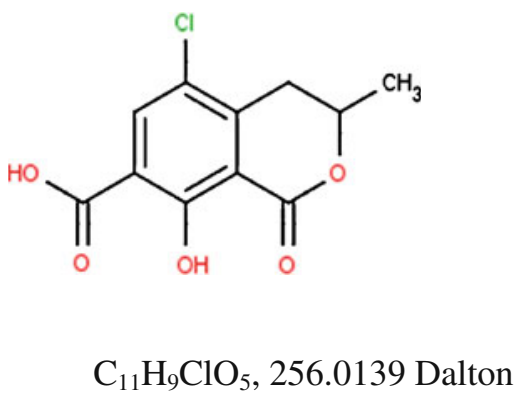

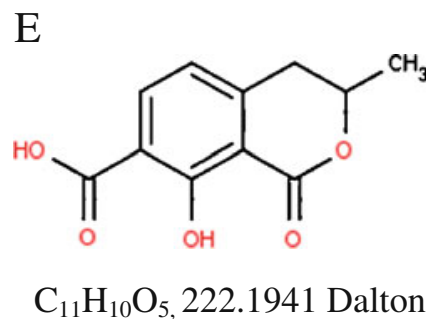

\section{Materials and methods}

\section{Materials}

Acetonitrile (ACN), methanol $(\mathrm{MeOH})$ and ToF-grade water were purchased from Biosolve (Valkenswaards, The Netherlands). Formic acid ( $\mathrm{HCOOH})$ and ethylene diamine were from Merck (Whitehouse Station, NJ, USA) and $\mathrm{N}$-(3dimethylaminopropyl)- $N$-ethylcarbodiimide hydrochloride (EDC), $\mathrm{NaHCO}_{3}$, Tween-20, OTA, OTB and $\mathrm{NaN}_{3}$ from Sigma-Aldrich Chemie (Zwijndrecht, The Netherlands). Beads (magnetic carboxylated microspheres (MagPlex ${ }^{\mathrm{TM}}$ no. 086)) and the sheath fluid were supplied by Luminex Corporation (Austin, TX, USA). Mabs (purified mouse anti-OTA IgG (201051-5G9)) were purchased from Soft Flow Biotechnology (Pécs, Hungary) and water was purified using a Milli-Q system (Millipore, Bedford, MA, USA). Protein LoBind Tubes $(1.5 \mathrm{~mL})$ were supplied by Eppendorf (Hamburg, Germany) and the LoBind 96-wells microplates by Greiner Bio-One B.V. (Alphen a/d Rijn, The Netherlands). The $N$-hydroxysulfosuccinimide sodium salt (sulfo-NHS) was provided by Fluka Analytical (Steiham, Switzerland). Amicon Ultra Ultracel $50 \mathrm{~K}$ centrifugal filter units were purchased from Millipore (Bedford, MA, USA) and all BCA reagents were from Thermo Scientific (Rockford,
IL, USA). R-PE was from Moss (Pasadena, MD, USA). Surface plasmon resonance (SPR) biosensor chips (CM5), the amine coupling kit (containing 0.1 M NHS, 0.4 M EDC, and $1 \mathrm{M}$ ethanolamine hydrochloride ( $\mathrm{pH} 8.5)$ ) were from GE Healthcare (Uppsala, Sweden).

Instrumentation

High-pressure liquid chromatography-triple-quadrupole mass spectrometry

A Waters (Milford, MA, USA) ACQUITY Ultra Performance LC (UPLC) system, consisting of a degasser, a binary gradient pump, an autosampler $\left(\right.$ at $10^{\circ} \mathrm{C}$ ) and a column oven $\left(\right.$ at $40^{\circ} \mathrm{C}$ ), was used. The sample injection volume was $50 \mu \mathrm{L}$ and the analytical column was an Xbridge $3.5 \mu \mathrm{m}$ C18, $2.1 \mathrm{~mm}$ I.D. $\times$ $100 \mathrm{~mm}$ from Waters. The UPLC system was coupled to a Micromass (Manchester, UK) Quattro Ultima tandem mass spectrometry (QqQ) system equipped with an electrospray interface (ESI). The two mobile phases used consisted of (A) $\mathrm{H}_{2} \mathrm{O} / \mathrm{HCOOH}(99.9 / 0.1 \% v / v)$ and (B) $\mathrm{MeOH} / \mathrm{HCOOH}$ $(99.9 / 0.1 \% v / v)$ and the flow rate was $0.3 \mathrm{~mL} / \mathrm{min}$. The gradient started at $100 \% \mathrm{~A}$ and was kept at this composition for $1 \mathrm{~min}$ and decreased linearly to $50 \% \mathrm{~A}$ in $2 \mathrm{~min}$. The mobile composition decrease to $0 \% \mathrm{~A}$ was done in $3 \mathrm{~min}$ and 
kept at $0 \% \mathrm{~A}$ for $7 \mathrm{~min}$ and returned to $100 \% \mathrm{~A}$ in $0.5 \mathrm{~min}$ with a final hold of $1.5 \mathrm{~min}$.

The LC was interfaced with the MS/MS system without a flow split. The mass spectrometer was operated in the positive ESI mode, which was found to be more sensitive than negative ESI in preliminary experiments, at a capillary voltage of $2.5 \mathrm{kV}$, cone voltage of $30 \mathrm{~V}$, a desolvation gas temperature of $350{ }^{\circ} \mathrm{C}$ and source temperature of $120{ }^{\circ} \mathrm{C}$. The desolvation gas was nitrogen $(600 \mathrm{~L} / \mathrm{h})$ and the collision-induced dissociation gas was argon at a pressure of $2.5 \times 10^{-3}$ mbar. The run time was $15 \mathrm{~min}$ and data acquisition for OTA was performed in multiple reaction monitoring mode (MRM) at transitions $m / z=404.2 \rightarrow 221.0$ and $m / z=404.2 \rightarrow 238.8$ using collision energy 35 and $30 \mathrm{eV}$, respectively. The absolute limit of detection (LoD) of OTA was determined at $10 \mathrm{pg}$ on-column $(S / N>6)$.

\section{Nano-liquid chromatography-quadrupole time-of-flight-mass spectrometry (nano-LC-Q-ToF-MS)}

The nanoACQUITY UPLC System of Waters consisted of a degasser, a binary gradient pump, a nano-autosampler (at $20^{\circ} \mathrm{C}$ ) and a column oven (at $60^{\circ} \mathrm{C}$ ). Lower autosampler temperature induced precipitation of particles in real sample extract causing system overpressure. The trapping column was a nanoAcquity UPLC HSS T3 $5 \mu \mathrm{m} \mathrm{C8}, 180 \mu \mathrm{m}$ I.D. $\times$ $20 \mathrm{~mm}$, and the analytical column was a nanoACQUITY UPLC BEH $1.7 \mu \mathrm{m} \mathrm{C18} \mathrm{column,} \mathrm{pore} \mathrm{size} 130 \AA, 75 \mu \mathrm{m} \mathrm{I}$. D. $\times 100 \mathrm{~mm}$, all from Waters. The nanoACQUITY UPLC System was coupled to a Xevo quadrupole time-of-flight (Q-ToF; from Waters) mass spectrometry system equipped with a nano-ESI interface without a flow split. The two mobile phases consisted of (A) $\mathrm{H}_{2} \mathrm{O} / \mathrm{HCOOH}(99.9 / 0.1 \% v / v)$ and (B) $\mathrm{MeOH} / \mathrm{HCOOH}(99.9 / 0.1 \% v / v)$ and the flow was $500 \mathrm{~nL} / \mathrm{min}$. After injection $(4 \mu \mathrm{L})$, the sample was preconcentrated on the trapping column at a flow rate of $10 \mu \mathrm{L} / \min (100 \% \mathrm{~A})$.

After a 3-min trapping time, the gradient started at 99\% A and was kept at this composition for 5 min and decreased linearly to $5 \% \mathrm{~A}$ in $5 \mathrm{~min}$. This mobile phase composition was kept for $12 \mathrm{~min}$ and returned to $100 \% \mathrm{~A}$ in $1 \mathrm{~min}$ with a final hold of $7 \mathrm{~min}$. The total run time was $33 \mathrm{~min}$. The mass spectrometer was operated in the positive ESI mode (again found to be more sensitive than negative ESI in preliminary experiments) at a capillary voltage of $2.8 \mathrm{kV}$, cone was at $40 \mathrm{~V}$ and source temperature was $80^{\circ} \mathrm{C}$. The purge gas was nitrogen $(50 \mathrm{~L} / \mathrm{h})$ and cone gas $10 \mathrm{~L} / \mathrm{h}$ and data acquisition was performed in full scan centroid mode. The detector, containing a $4 \mathrm{GHz}$ TDC, was set to accumulate spectra during $0.3 \mathrm{~s}$ in full scan mode at a resolution of 10,000 FWHM. The dynamic range enhancement option was applied to achieve accurate mass measurements over a wide concentration range. A $2 \mathrm{ng} / \mu \mathrm{L}$ standard solution of leucine-enkephalin was introduced as a lockmass via the lock-spray needle (capillary voltage $2.8 \mathrm{kV}$ and cone voltage $40 \mathrm{~V}$ ) at a flow rate of $500 \mathrm{~nL} / \mathrm{min}$.

\section{Other instruments}

The Luminex FM-3D flow cytometer with Xponent System 2.0 control software was purchased from Luminex Corporation (Austin, TX, USA). The NanoDrop ND-1000 spectrophotometer was from Thermo Scientific (Rockford, IL, USA) and the Biacore 3000 SPR biosensor from GE Healthcare (Uppsala, Sweden). The automated magnetic wash station BioPlex ${ }^{\mathrm{TM}}$ Pro II, with a magnetic carrier, was from BioRad Laboratories B.V. (Veenendaal, The Netherlands) and the magnetic separator rack DynaMag-2 ${ }^{\text {TM }}$ from Invitrogen Dynal (Oslo, Norway). The microtiter plate vari-shaker was from Dynatech (Alexandria, VI, USA) and the REAX2 head-over-head shaker from Heidolph (Schwabach, Germany). The Eppendorf 5810 R centrifuge, using the A-4-62 rotor, was purchased from VWR International (Amsterdam, the Netherlands) and the test tube rotator from Snijders (Tilburg, The Netherlands).

\section{Methods}

\section{SPR biosensor immunoassay}

For testing several dissociation conditions of OTA from the Mabs, OTA was immobilised onto the carboxymethylated dextran surface of a CM5 biosensor chip. For this, the CM5 sensor chip surface was activated with $50 \mu \mathrm{L}$ of a mixture of $0.4 \mathrm{M}$ EDC and $0.1 \mathrm{M}$ NHS $(1: 1, v / v)$ during $15 \mathrm{~min}$ at room temperature (RT). The chip surface was washed with water and dried under a stream of nitrogen gas. To the chip, $50 \mu \mathrm{L}$ of $1 \mathrm{M}$ ethylene diamine ( $\mathrm{pH}$ 8.5) was added and after 15 min incubation at RT, the chip was washed with water and dried under a stream of nitrogen gas. OTA was immobilised on the activated sensor surface using the following procedure. OTA $(1 \mathrm{mg})$ was dissolved in $0.2 \mathrm{~mL}$ ACN/water $(80: 20, v / v)$ and $0.2 \mathrm{~mL}$ sodium carbonate buffer (pH 9.6) and $50 \mu \mathrm{L}$ was mixed with $50 \mu \mathrm{L}$ EDC and $50 \mu \mathrm{L}$ NHS and after incubation at RT for $45 \mathrm{~min}$, this mixture $(50 \mu \mathrm{L})$ was added to the activated chip. After incubation of $45 \mathrm{~min}$ at RT, the chip was washed with water, dried under a stream of nitrogen and docked into the Biacore 3000. Mab dilutions in HBS-EP buffer were injected $(20 \mu \mathrm{L}$ at $20 \mu \mathrm{L} / \mathrm{min})$ over the chip surface which resulted in OTA Mab complexes. Several solutions (10 mM $\mathrm{HCl}, \mathrm{ACN} / \mathrm{H}_{2} \mathrm{O} / \mathrm{HCOOH}(20 / 79 / 1 \% v / v / v), \mathrm{HCOOH} / \mathrm{H}_{2} \mathrm{O}$ $(1 / 99 \% v / v), \mathrm{ACN}$ and $\mathrm{MeOH})$ were injected $(10 \mu \mathrm{L})$ for testing the dissociation of the Mabs from the sensor chip. The most suitable dissociation solution was used later on during immunoaffinity extraction of OTA from wheat and 
cereal to dissociate OTA from the immunomagnetic microbeads.

\section{Preparation of the anti-OTA Mab-coated superparamagnetic} beads

Superparamagnetic bead set no. 86 was coated with antiOTA Mabs using the slightly modified two-step carbodiimide coupling protocol provided by Luminex ${ }^{\circledR}$. This covalent coupling was based on conjugating the amino groups of the anti-OTA Mab to the carboxylic groups on the surface of the beads. In short, the stock of beads (suspension containing $1.25 \times 10^{7}$ beads $/ \mathrm{mL}$ ) was resuspended by vortexing for $5 \mathrm{~min}$. From this stock, $400 \mu \mathrm{L}$ (containing $5 \times 10^{6}$ beads) was transferred to a protein LoBind tube in which the beads were concentrated in the magnetic separator rack in $1 \mathrm{~min}$. After gently removing of the supernatant, the pellet was washed by resuspending in $100 \mu \mathrm{L}$ activation buffer $\left(0.1 \mathrm{M} \mathrm{NaH}_{2} \mathrm{PO}_{4}, \mathrm{pH}\right.$ 6.2). The beads were concentrated in the magnetic separator rack and the supernatant was removed. The pellet was resuspended in $80 \mu \mathrm{L}$ of activation buffer $(0.1 \mathrm{M}$ $\mathrm{NaH}_{2} \mathrm{PO}_{4}, \mathrm{pH}$ 6.2). Solutions of sulfo-NHS and EDC (both at $50 \mathrm{mg} / \mathrm{mL}$ ) were prepared just before adding $10 \mu \mathrm{L}$ of each to the $80 \mu \mathrm{L}$ bead suspension. The concentrations of both these solutions were $50 \mathrm{mg} / \mathrm{mL}$ made in $\mathrm{H}_{2} \mathrm{O}$. The beads were incubated in the dark at $\mathrm{RT}$ for $20 \mathrm{~min}$. The activated beads were concentrated by the magnet and washed by adding $250 \mu \mathrm{L}$ of $100 \mathrm{mM}$ MES (2- $N$-morpholino ethanesulfonic acid) buffer at $\mathrm{pH}$ 5. This wash step was performed twice. To the activated and precipitated beads, first, $100 \mu \mathrm{L}$ of $100 \mathrm{mM}$ MES buffer was added to prevent the beads from becoming dry then a solution containing $100 \mu \mathrm{g}$ of the anti-OTA Mab in $400 \mu \mathrm{L}$ of $100 \mathrm{mM}$ MES buffer was added. The suspension was vortexed shortly and incubated for $2 \mathrm{~h}$ under mixing by rotation in a test tube rotator at room temperature in the dark. Following the incubation, the supernatant containing unbound anti-OTA Mabs was removed and the beads were washed three times with storage buffer (the first wash with $500 \mu \mathrm{L}$, the remaining two steps with $1 \mathrm{~mL}$ ) consisting of PBS $(5.4 \mathrm{mM}$ $\mathrm{Na}_{2} \mathrm{HPO}_{4}, 1.3 \mathrm{mM} \mathrm{KH} \mathrm{PO}_{4}, 150 \mathrm{mM} \mathrm{NaCl}, 3 \mathrm{mM} \mathrm{KCl}$, $\mathrm{pH} 7.4$ ) to which, $0.02 \%$ Tween- 20 and $0.05 \% \mathrm{NaN}_{3}$ were added. Finally, the beads were suspended in $500 \mu \mathrm{L}$ of the storage buffer and stored at $4{ }^{\circ} \mathrm{C}$ in dark until used (counted $3.5 \times 10^{6}$ beads per $500 \mu \mathrm{L}$ ). Usually, after incubation, bovine serum albumin (BSA) is used to block the free activated sites of the bead surface. In this study, no blocking procedure was used because BSA might contribute to non-specific binding of OTA [32]. The possible non-specific binding of OTA to the unblocked bead surface was tested.

\section{OTA-PE conjugation}

The OTA-PE conjugate was prepared according to a minor modified protocol of Kawamura et al. [31] and was based on conjugating the carboxylic group of OTA to the amino groups of R-PE. In short, $3.5 \mathrm{mg}$ of R-PE was dissolved in $4 \mathrm{~mL}$ of $0.1 \mathrm{M} \mathrm{NaCl}$. To this solution, $50 \mu \mathrm{L}$ ethanol which contained $1 \mathrm{mg}$ of OTA was added dropwise. To this mixture, $3 \mathrm{~mL}$ of $0.1 \mathrm{M}$ phosphate buffer $(\mathrm{pH} 7)$ containing $10 \mathrm{mg}$ of EDC was added to initiate the coupling. This reaction was incubated for $24 \mathrm{~h}$ at room temperature while stirring in the dark. Following the incubation, the mixture was added to a $50-\mathrm{kDa}$ microcon filter to remove uncoupled free OTA from the OTA-PE conjugate by centrifuging at $12,000 \times \mathrm{g}$ for $10 \mathrm{~min}$ after which the OTA-PE was reconstituted in $1 \mathrm{~mL}$ PBS buffer. In total, five subsequent wash steps were performed to remove all unbound OTA. Finally, after the last wash step, OTA-PE was reconstituted in $2 \mathrm{~mL}$ of PBS buffer containing $0.05 \%$ $\mathrm{NaN}_{3}$ and stored in the dark at $4{ }^{\circ} \mathrm{C}$.

\section{Protein analysis}

$B C A$ The BCA protocol consisted of the following steps; $10 \mu \mathrm{L}$ sample solution was added to a microtiter plate $(n=2)$. Then, $200 \mu \mathrm{L}$ of a mixture, consisting of an alkaline agent, bicinchoninic acid (BCA) and $\mathrm{CuSO}_{4}$ (reduced to $\mathrm{Cu}^{1+}$ by proteins), was added to the samples and the calibration curve. The reagent is responsible for colour change by chelating 2 BCA molecules to $\mathrm{Cu}^{1+}$ ions. The calibration curve was made by diluting an immunoglobulin $\mathrm{G}$ (IgG) with PBS buffer. Following the addition of reagents, the microtiter plate was incubated at $37{ }^{\circ} \mathrm{C}$ during $30 \mathrm{~min}$ after which the microtiter plate was cooled for 5 min at RT and the concentration of proteins was measured using an UV microtiter plate reader at $562 \mathrm{~nm}$.

NanoDrop First, one blank UV-absorbance measurement with $0.5 \mu \mathrm{L} \mathrm{H}_{2} \mathrm{O}$ was performed at $280 \mathrm{~nm}$ after which $0.5 \mu \mathrm{L}$ of sample solution was measured at $280 \mathrm{~nm}$. The samples (antibody solutions), before and after coupling, were measured in the Nanodrop spectrophotometer in duplicate to determine coupling efficiency.

\section{OTA extraction from wheat and cereal samples}

One gram of sample (either wheat or cereal) was weighed into a $50-\mathrm{mL}$ tube and $10 \mathrm{~mL}$ of a $1 \%$ aqueous solution of $\mathrm{NaHCO}_{3}$ ( $\mathrm{pH}$ 8.1) was added to extract ochratoxins from wheat or cereal samples. The tubes were vortexed for $10 \mathrm{~s}$ and placed into the head-over-head shaker (rotating slowly) for $30 \mathrm{~min}$. After shaking, the tubes were centrifuged for $5 \mathrm{~min}$ at $3500 \mathrm{rpm}$. For the FCIA, $40 \mu \mathrm{L}$ of the supernatant was used 
(either diluted to fit in the calibration curve or undiluted). For nano-LC-Q-ToF-MS-based identification, instead of $40 \mu \mathrm{L}$, $1 \mathrm{~mL}$ of extract was used which corresponded to $100 \mathrm{pg}$ OTA from a sample containing $1 \mathrm{ng} / \mathrm{g}$ OTA.

\section{Flow cytometry immunoassay protocol}

First, $40 \mu \mathrm{L}$ of either sample or standard solution was preincubated for $15 \mathrm{~min}$ in a well of a LB 96-well microtiter plate to which approximately 2,000 beads coated with antiOTA Mab were added. After the pre-incubation, $10 \mu \mathrm{L}$ of diluted OTA-PE (125 times diluted in $\mathrm{NaHCO}_{3}$ buffer ( $\mathrm{pH}$ 8.1)) was added to each well. This mixture was incubated for $30 \mathrm{~min}$ on a plate shaker at RT in the dark. After these incubations, a washing step with PBS-Tween-20 (PBST) was applied to remove the excess unbound bioreagents and matrix compounds. The wash step was carried out with the magnetic washing plate carrier of the automated wash station. After washing, the beads were resuspended in $100 \mu \mathrm{L}$ of PBST and the measurement in the Luminex ${ }^{\circledR}$ was done in $<60 \mathrm{~s}$ using $75 \mu \mathrm{L}$ per well. To prepare a dose-response calibration curve in buffer $\left(\mathrm{NaHCO}_{3}, \mathrm{pH} 8.1\right)$ or in blank wheat extract, a dilution series of OTA (0.0001-1000 ng/mL) was prepared in buffer or in blank wheat extract and the results were fitted using the five parameter curve fitting in the GraphPad Prism software of GraphPad Software Inc. (La Jolla, CA, USA).

\section{Immunoaffinity isolations of OTA for LC-MS detection}

Of the anti-OTA Mab-coated bead stock suspension (containing $3.5 \times 10^{6}$ beads per $500 \mu \mathrm{L}$ ), $100 \mu \mathrm{L}$ beads was transferred into a $1.5-\mathrm{mL}$ Eppendorf tube $\left(7.0 \times 10^{5}\right)$. The coated beads were trapped by applying the magnetic separator rack for $60 \mathrm{~s}$ and the supernatant was removed. One hundred to $1,500 \mu \mathrm{L}$ of either buffer containing 100 $300 \mathrm{pg}$ OTA or sample supernatant was added to the beads after which the incubation (tested 1-60 min) was done under gently vortexing. After the incubation, the magnetic separator rack was applied for $60 \mathrm{~s}$ and the supernatant was removed gently. To remove matrix compounds, the trapped beads were washed with $100 \mu \mathrm{L} \mathrm{NaHCO} 3$ buffer $(\mathrm{pH} 8.1)$ by vortexing for $5 \mathrm{~min}$. The magnetic separator rack was applied for $60 \mathrm{~s}$ to concentrate beads followed by removal of supernatant. This wash step was repeated once and after the final wash step, $100 \mu \mathrm{L}$ of the dissociation solvent $\left(\mathrm{ACN} / \mathrm{H}_{2} \mathrm{O} / \mathrm{HCOOH}(20 / 79 / 1 \% \quad v / v / v)\right)$ was added to the trapped beads to dissociate OTA from the beads. This was achieved by gentle vortexing for $5 \mathrm{~min}$ after which the magnetic separator rack was applied for $60 \mathrm{~s}$ and the supernatant (OTA-containing eluate) was transferred into an LC-QqQ-MS vial. For nano-LC-Q-ToF experiments, $25 \mu \mathrm{L}$ of dissociation solvent was used.

\section{Results and discussion}

Coupling efficiency of anti-OTA Mabs to the beads

For the FCIA and the immunoaffinity isolation, the same beads were coated with the same anti-OTA Mabs ensuring a uniform bioaffinity during the screening and the isolation prior to MS confirmation or identification. Several Mabs were tested in the FCIA (data not shown) and the anti-OTA Mab from Soft Flow was selected because of its highest sensitivity and its cross-reactivity towards OTB. The amount of antibodies immobilised determines the amount of beads needed for isolation purposes. Following the Luminex ${ }^{\circledR}$ coupling protocol for proteins to the MagPlex ${ }^{\mathrm{TM}}$ beads, $0.4 \mathrm{~mL}$ of $0.25 \mathrm{mg} / \mathrm{mL}$ anti-OTA Mab was added to $5 \times 10^{6}$ activated beads. To determine the coupling efficiency, antibody concentrations were measured in the solutions before and after six immobilisations by two different protein determination techniques: BCA $[33,34]$ and NanoDrop [35]. With the BCA method, average protein concentrations of $0.28 \pm 0.01$ and $0.17 \pm 0.01 \mathrm{mg} / \mathrm{mL}$ were found in the solutions before and after coupling, respectively (BCA usually overestimates glycoprotein concentration [36]). Therefore, the average coupling efficiency was calculated to be $39 \%$. With the NanoDrop, the coupling efficiency was determined to be $44 \%$. Based on these two different techniques for protein analysis, from the absolute amount of Mab $(100 \mu \mathrm{g})$ added to $5 \times 10^{6}$ beads, between 39 and $44 \mu \mathrm{g}$ was coupled.

\section{Flow cytometric screening}

For the rapid screening of OTA in wheat and cereal samples, a direct inhibition FCIA with Mab-coated superparamagnetic beads and OTA-PE, as the label for detection, was developed. This direct assay format is less laborious and faster, compared to the indirect assay format developed recently [17], because only two (instead of three) incubation steps and one (instead of two) washing step are required. During the development of the direct inhibition method, various steps and parameters were optimised using an OTA concentration range of $0.0001-1000 \mathrm{ng} / \mathrm{mL}$. The pre-incubation step was performed at different times $(15,30,60 \mathrm{~min})$ and $15 \mathrm{~min}$ was found to be sufficient. Omitting the pre-incubation step influenced the precision negatively at low OTA levels. The effect of the amount of beads $(1,000$ or $2,000 /$ well $)$ was tested and the latter was optimal. Following this, different dilutions of OTA-PE (250, 125, 62.5 times) were tested and the 125 times dilution was optimal with regard to the sensitivity of the assay and aiming for an average final response of 2,000 mean fluorescent intensity (MFI). The optimum OTA-PE incubation time was $30 \mathrm{~min}(15,30,60 \mathrm{~min}$ tested). After 
the incubation, a washing step with PBST in the magnetic washer was performed. Two wash buffers (PBS and PBST) were tested to remove matrix compounds and PBST was found most suitable as wash buffer and the same buffer was used to resuspend the beads. Finally, the measurement in the Luminex was optimised by testing the injection volumes (50 and $75 \mu \mathrm{L}$, latter was optimum), injection times (30 and $60 \mathrm{~s}$, latter was optimum) and detector settings (low and high detector voltage, latter was used). For the extraction of ochratoxins from wheat and cereal samples, various ratios of acetonitrile/water and methanol/ water with and without formic acid were tested. Further, $\mathrm{NaHCO}_{3}$ buffer ( $\mathrm{pH}$ 8.1) was tested and was found to be the most suitable extraction solution because in contrast to other extraction solutions, no false suspect results were produced with this FCIA. The final protocol with selected optimal conditions is described in the "Materials and methods" section. This protocol resulted in a dose-response curve for OTA in buffer with a sensitivity at $50 \%$ inhibition $\left(\mathrm{IC}_{50}\right)$ of $0.3 \mathrm{ng} / \mathrm{mL}$ (Fig. 2a), which is comparable to the sensitivity obtained in the indirect format [17], but more sensitive than ELISAs $\left(\mathrm{IC}_{50} 0.45-400 \mathrm{ng} / \mathrm{mL}\right)[37,38]$, the used SPR biosensor immunoassay ( $\mathrm{IC}_{50}$ around $5 \mathrm{ng} / \mathrm{mL}$ ) and the non-instrumental dipstick OTA assay [39] (cut-off level of $3.2 \mathrm{ng} / \mathrm{mL}$ ).
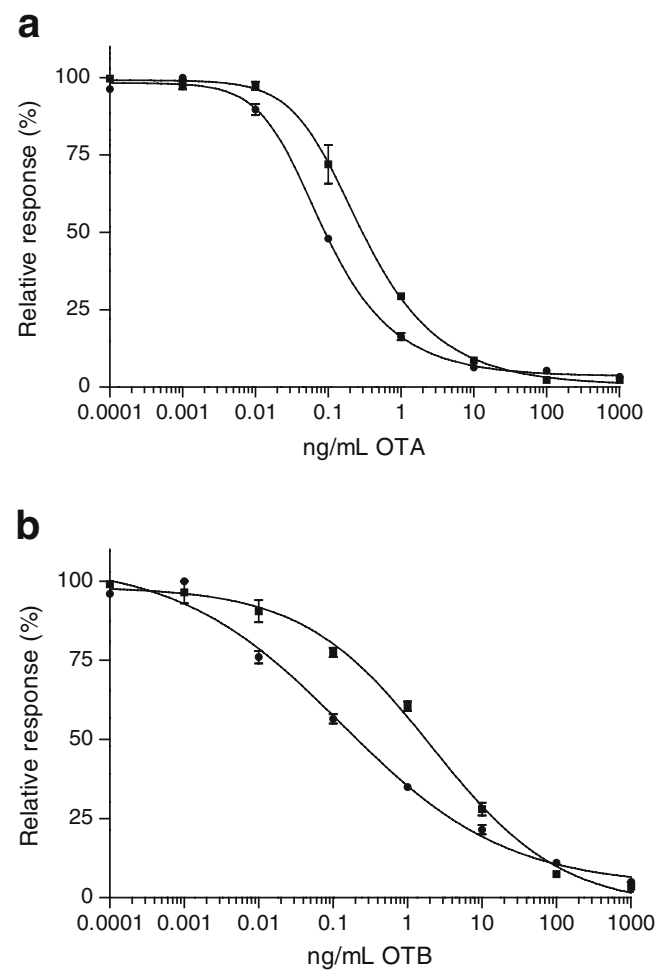

Fig. 2 a Average dose-response curves $(n=2)$ of OTA in buffer (filled square; $\mathrm{IC}_{50}=0.30 \mathrm{ng} / \mathrm{mL}$ ) and in wheat extract (filled circle; $\mathrm{IC}_{50}=0.09 \mathrm{ng} / \mathrm{mL}$ ) obtained in FCIA screening assay. b Average dose-response curves $(n=2)$ of OTB in buffer (filled square; $\mathrm{IC}_{50}=2.1 \mathrm{ng} / \mathrm{mL}$ ) and wheat extract (filled circle; $\mathrm{IC}_{50}=0.13 \mathrm{ng} / \mathrm{mL}$ )
The dose-response curve in wheat extract (Fig. 2a) showed a slightly better sensitivity with an $\mathrm{IC}_{50}$ of $0.09 \mathrm{ng} / \mathrm{mL}$ or $0.9 \mathrm{ng} / \mathrm{g}$ in the wheat sample. Due to this matrix effect, (semi-)quantification of OTA in wheat was performed with a dose-response curve in a blank wheat extract which showed good precision and a wide measurement range ( 0.01 to $1 \mathrm{ng} / \mathrm{mL}$ or 0.1 to $10 \mathrm{ng} / \mathrm{g}$ ) which is adequate for the detection at even the lowest ML levels of 3 or $5 \mathrm{ng} / \mathrm{g}$.

The assay was also tested for cross-reactivity with OTB and Fig. $2 b$ presents the dose-response curves in buffer and blank wheat extract. According to the $\mathrm{IC}_{50}$ values for OTB in buffer and wheat extract of 2.1 and $0.13 \mathrm{ng} / \mathrm{mL}$, respectively, the cross-reactivities compared to OTA were calculated as $14 \%$ and $69 \%$, respectively, which are higher compared to the supplier's data obtained with ELISA $(9.2 \%$ in buffer). Under current buffer condition, the OTB doseresponse curve showed a wide measurement range, in which (semi-)quantification is allowed with good precision.

Assigned blank wheat samples $(n=11)$ without and with the addition of OTA ( 1 and $5 \mathrm{ng} / \mathrm{g}$ ) were analysed with the FCIA screening assay. These blank samples were also analysed by an in-house-validated LC-QqQ-MS method and ten of them were found negative $(<0.6 \mathrm{ng} / \mathrm{g})$. Figure 3 shows that there are clear differences in responses MFI between those ten blank wheat samples and the spiked wheat samples at different levels. The results obtained with these ten blank wheat samples, in combination with calibration curves in a blank wheat extract, were used to calculate the LoD of the screening method (the concentration at the average maximum response minus $3 \times \mathrm{SD}$ ) which was calculated as $0.15 \mathrm{ng} / \mathrm{g}$. The concentrations found in the wheat samples spiked at $1 \mathrm{ng} / \mathrm{g}$ varied between 0.3 and $0.6 \mathrm{ng} / \mathrm{g}$ with an average of $0.5 \pm 0.08 \mathrm{ng} / \mathrm{g}$ and in the wheat sample spiked at $5 \mathrm{ng} / \mathrm{g}$ between 2.5 and $4 \mathrm{ng} / \mathrm{g}$ with an average of $3.0 \pm 0.37 \mathrm{ng} / \mathrm{g}$. These results show that this screening assay is semi-quantitative and suitable to identify suspect wheat samples at the required ML's of 3 or $5 \mathrm{ng} / \mathrm{g}$.

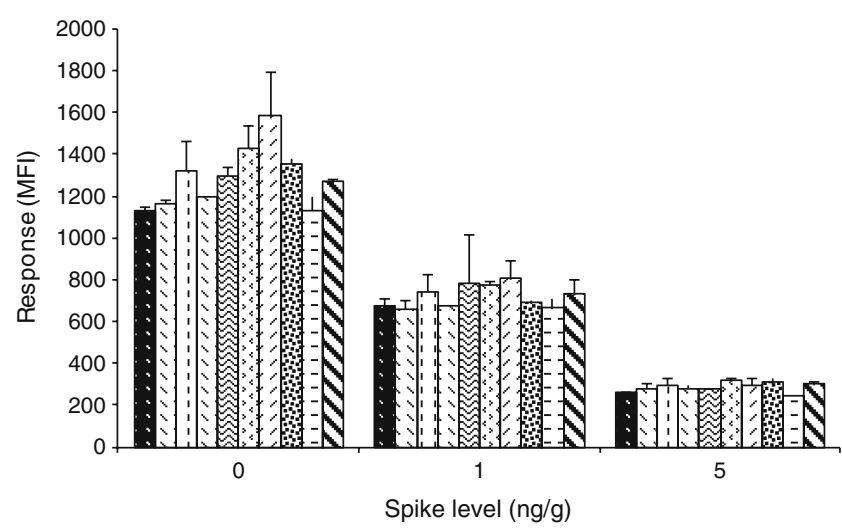

Fig. 3 Average FCIA responses $(n=2)$ obtained with the ten blank wheat samples $(0 \mathrm{ng} / \mathrm{g})$ and blank wheat spiked with OTA at 1 and $5 \mathrm{ng} / \mathrm{g}$ 
The eleventh wheat sample was found suspect in the FCIA screening $(5.6 \pm 0.9 \mathrm{ng} / \mathrm{g})$ and the OTA concentration found with the LC-QqQ-MS-based chemical method in MRM mode was $15 \mathrm{ng} / \mathrm{g}$. Primary extraction recovery of OTA (50-60\%) from wheat and cereal remained uncorrected in the FCIA procedure. Three naturally OTA-contaminated cereal samples from a collaborative study were kindly provided by the IRMM (Geel, Belgium); sample 1 (35 ng/g), sample $2(190 \mathrm{ng} / \mathrm{g}$, from proficiency test) and sample 3 $(290 \mathrm{ng} / \mathrm{g})$. In the semi-quantitative screening method, all incurred cereal samples were found suspect and after analysing diluted extracts, the concentrations found were 35 (sample 1), 60 (sample 2) and $110 \mathrm{ng} / \mathrm{g}$ (sample 3). The samples were also re-analysed with the in-house validated LCQqQ-MS method and OTA concentrations found were 45 (sample 1), 171 (sample 2) and $397 \mathrm{ng} / \mathrm{g}$ (sample 3).

Immunoaffinity microbead isolation method

For future identification purposes of OTA and crossreacting analogues in wheat and cereal sample extracts by means of nano-LC-Q-ToF, a microbead-based immunoaffinity isolation method was developed. For this isolation, the same, but different amounts, Mab-coated beads were used as applied in the screening method. Most of the optimisation experiments were performed with an LCQqQ-MS system operated in the MRM mode, because of its high sensitivity (absolute 10 pg of OTA) and wide availability.

\section{Dissociation conditions}

In order to find a suitable dissociation condition of the immunomagnetic isolated OTA, an SPR-based biosensor (Biacore 3000) was used in combination with a biosensor chip coated with OTA. Note that this SPR set-up is in reversed assay format compared to the applied immunoaffinity isolation method; however, in both methods identical immunochemistry is involved to dissociate the Mab-OTA complex. Injections of anti-OTA Mabs $(10 \mu \mathrm{l}$ of $0.1 \mathrm{mg} / \mathrm{ml}$ ) onto this chip resulted in high responses (9,400 response units) of bound antibodies which could be dissociated under mild acidic conditions (e.g. a few injections $(10 \mu \mathrm{L})$ of $10 \mathrm{mM} \mathrm{HCl})$. Due to this $\mathrm{pH}$ shift, protein charge and conformation changed causing the dissociation of the OTA Mab complex. Alternative solvents, $\mathrm{HCOOH} / \mathrm{H}_{2} \mathrm{O}, \mathrm{MeOH}(0-100 \%)$ and $\mathrm{ACN}$ $(0-100 \%)$ were tested as well (see "Methods", SPR biosensor) and the mixture of $\mathrm{ACN} / \mathrm{H}_{2} \mathrm{O} / \mathrm{HCOOH}(20 /$ $79 / 1 \% v / v / v$ ) worked out well and was preferred because of better compatibility with LC-MS. Either 25 or $100 \mu \mathrm{L}$ of this dissociation solution was used in the immunomagnetic microbead isolation method.
Immunoaffinity capture efficiency and capacity

To determine the minimum amounts of immunoaffinity beads necessary to capture a reasonable amount of OTA $(100 \mathrm{pg})$, the capture efficiency had to be determined. This $100 \mathrm{pg}$ of OTA was chosen because it can easily be detected by the MS (LoD of $10 \mathrm{pg}$ ) and it corresponds with the amount of OTA in $1 \mathrm{~mL}$ of extract of a positive sample incurred at $1 \mathrm{ng} / \mathrm{g}$ level. For this experiment, $100 \mathrm{pg}$ of OTA was added to different amounts of beads $\left(1.4 \times 10^{6}\right.$, $7.0 \times 10^{5}, 3.5 \times 10^{5}, 1.75 \times 10^{5}, 8.8 \times 10^{4}$ and 0 beads). The 0 beads were used as blank control to prove that OTA was not bound to the test tubes. The $100 \mathrm{pg}$ were offered to the beads in a fixed final volume of $100 \mu \mathrm{L}$ and incubated for $60 \mathrm{~min}$ at RT under mild mixing. After capturing and washing, the captured OTA was dissociated from the beads by the addition of $100 \mu \mathrm{L} \mathrm{ACN} / \mathrm{H}_{2} \mathrm{O} / \mathrm{HCOOH}(20 / 79 / 1 \%$ $v / v / v)$ dissociation solution of which $50 \mu \mathrm{L}$ were injected in the LC-QqQ-MS. Figure 4 shows the amounts of OTA dissociated from the various amounts of beads. OTA was not found in the control, which proves that the Mab-coated beads are responsible for capturing OTA. To capture most of the $100 \mathrm{pg}$ OTA added, at least $1.75 \times 10^{5}$ beads were necessary. The dissociated amount of OTA decreased with lower amounts of beads (to $64 \mathrm{pg}$ using $8.8 \times 10^{4}$ beads), and the precision decreased significantly. Further, plain beads $\left(3.8 \times 10^{5}\right)$, which were activated but no Mab was added, and plain beads $\left(3.8 \times 10^{5}\right)$ which did not contain Mab but were blocked with BSA were tested with $100 \mathrm{pg}$ OTA and no OTA was found in the dissociated fraction. This indicates that the affinity capture of OTA was Mabspecific and OTA was not captured by BSA when used as blocking agent, probably because a lower amount of BSA $(0.1 \mathrm{mg})$ was used compared to Hong et al. [32] who used several milligrams of BSA to capture OTA. The bead capacity was determined with a fixed amount of beads $\left(7.0 \times 10^{5}\right)$ and various amounts of OTA $(100,300,900$ and

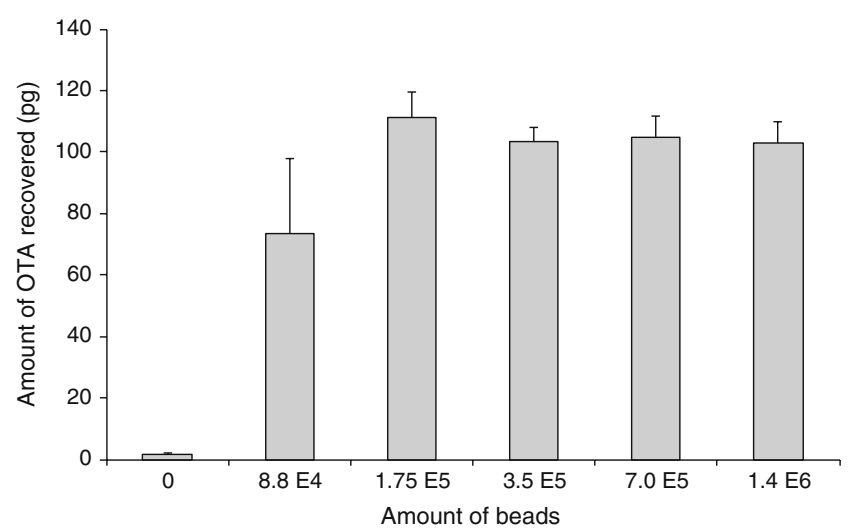

Fig. 4 Average amounts of OTA $(n=3)$ recovered from different amounts of beads after incubation with 100 pg OTA 


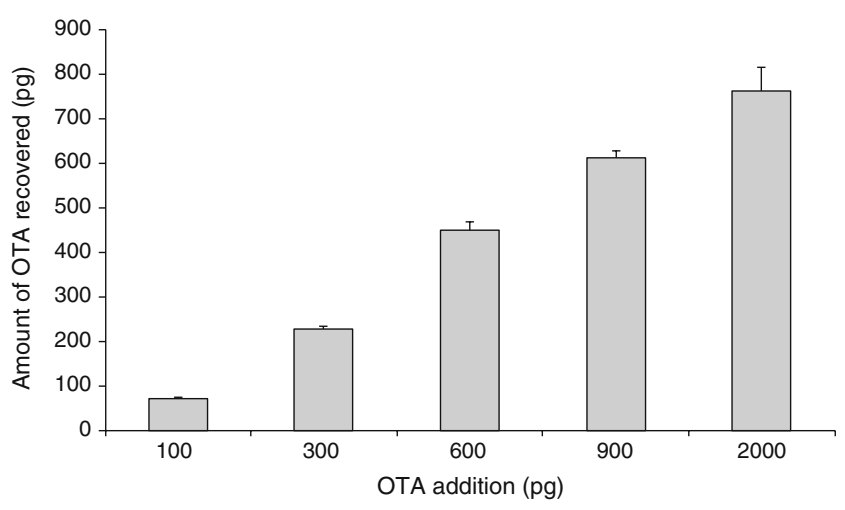

Fig. 5 Average amounts of OTA $(n=3)$ dissociated after the addition of different amounts of OTA to a fixed number of beads $\left(7.0 \times 10^{5}\right)$

$2,000 \mathrm{pg}$ ). Figure 5 shows that the overall capturing plus dissociation efficiency was $>75 \%$ when 100,300 and $600 \mathrm{pg}$ was incubated with $7.0 \times 10^{5}$ beads. This recovery decreased to about $65 \%$ and $<40 \%$ with 900 and $2,000 \mathrm{pg}$ of OTA, respectively. The maximum amount of OTA which could be bound to and recovered from this amount of beads under the conditions mentioned was estimated to be around $750 \mathrm{pg}$.

\section{Incubation times and volumes}

So far, an incubation time of 60 min was used (also used in the FCIA previously) and the influence of the applied incubation time $(1,5,30$ and $60 \mathrm{~min})$ on the efficiency of
$7.0 \times 10^{5}$ beads to capture $100 \mathrm{pg}$ of OTA was determined in duplicate. Minor differences were observed in recovered OTA quantities (92-105 pg), which proves the possible use of a very short incubation time (1 min) for immunoaffinity isolation of OTA from samples. The influence of incubation volumes on the capture efficiency of $7.0 \times 10^{5}$ beads was also tested, because in a real-life situation it is possible that more sample volume is required $(>100 \mu \mathrm{L})$ to capture the minimum amount of OTA which is detectable by the LCMS. In this experiment, $100 \mu \mathrm{L}$ incubation volumes containing 100 pg OTA was used as reference and 50, 500 and $1,500 \mu \mathrm{L}$ incubation volumes were tested with an incubation time of $60 \mathrm{~min}$ : incubation volumes of 500 and $1,500 \mu \mathrm{L}$ gave similar results as the $100 \mu \mathrm{L}$ incubation volume. By reducing the incubation volume to $50 \mu \mathrm{L}$, the overall recoveries decreased $(<40 \%)$ and the precision decreased significantly. Possibly, the beads and OTA were not mixed well in $50 \mu \mathrm{L}$ when vortexed during the incubation step. Therefore, incubation volumes of 100,500 and $1,500 \mu \mathrm{L}$ were considered applicable.

\section{Nano-LC-Q-ToF-MS-based identification of ochratoxins}

The three suspect cereal samples and one positive and one blank wheat sample were subjected to the immunoaffinity isolation after which the obtained extracts were injected into the nano-LC-Q-ToF-MS system. Figure 6 shows the chromatogram and mass spectra of cereal 3 sample.
Fig. 6 Chromatograms and mass spectra of cereal 3 containing OTA (A) and OTB (B)
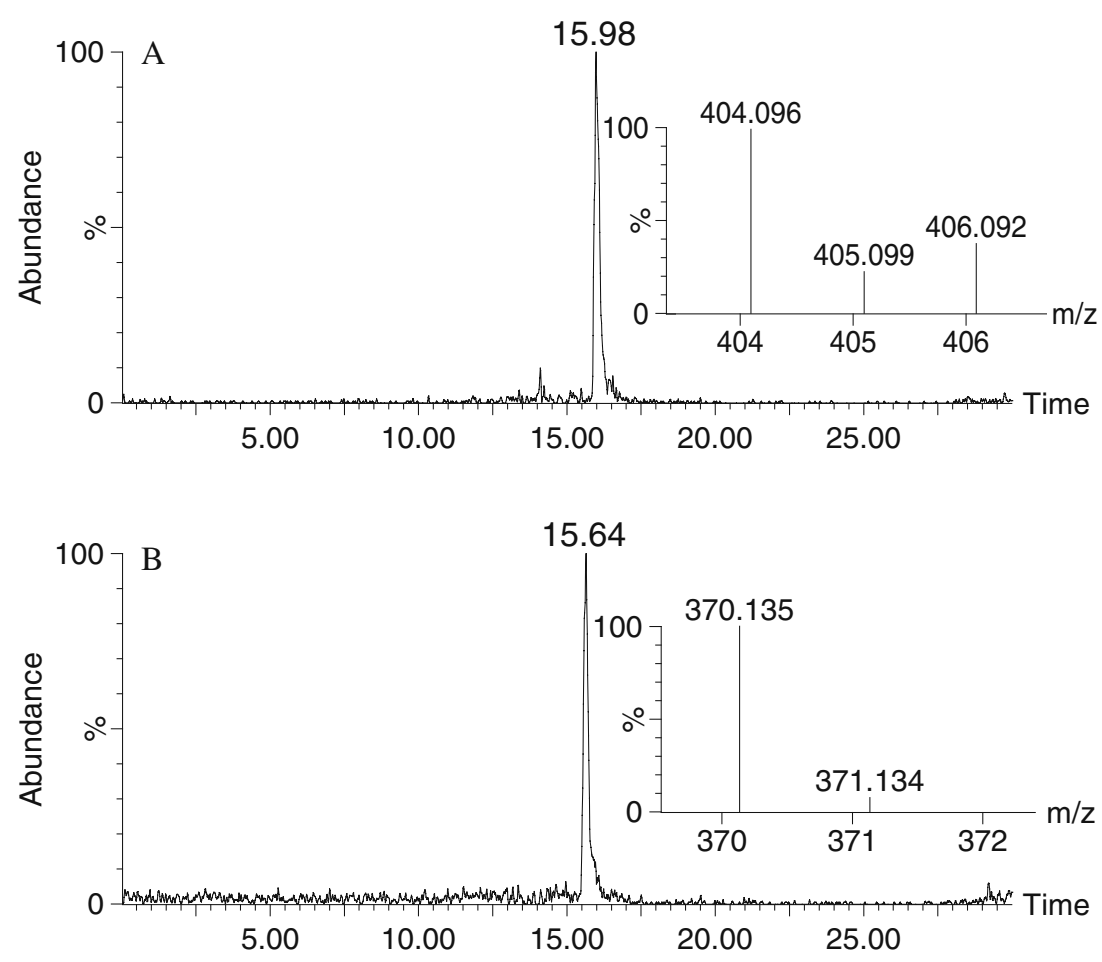
Table 1 Measured retention time and mass error of OTA in $1 \mathrm{ng} / \mathrm{mL}$ standard and cereal sample

\begin{tabular}{llllll}
\hline $\begin{array}{l}\text { Theoretical } \\
{[\mathrm{M}+\mathrm{H}]^{+}}\end{array}$ & Measurement & $\begin{array}{l}T_{\mathrm{R}} \\
(\mathrm{min})\end{array}$ & $\begin{array}{l}\text { Experimental } \\
{[\mathrm{M}+\mathrm{H}]^{+}}\end{array}$ & $\begin{array}{l}\text { Mass error } \\
(\mathrm{ppm})\end{array}$ & $\begin{array}{l}\text { Elemental composition } \\
{[\mathrm{M}+\mathrm{H}]^{+}}\end{array}$ \\
\hline 404.0901 & Standard & 15.98 & 404.0966 & -16 & $\mathrm{C}_{20} \mathrm{H}_{19} \mathrm{ClNO}_{6}$ \\
$406.0881\left({ }^{37} \mathrm{Cl}\right)$ & & & 406.0937 & -16 & $\mathrm{C}_{20} \mathrm{H}_{19} \mathrm{ClNO}_{6}$ \\
& Sample & 15.98 & 404.0958 & -14 & -11 \\
\hline
\end{tabular}

${ }^{a}$ OTA was identified on the basis of measured accurate mass and isotopic patterns using the following elemental composition limits: C 1-22, $\mathrm{H} 1-22$, $\mathrm{N}$ 1-5, O 1-9 and Cl 1. OTA was the first realistic option within calculated results with reasonable double bond equivalents

Figure 6 demonstrates that OTA was found and identified in cereal 3. This means that the positive response found in the FCIA was indeed caused by OTA, as expected. Moreover, due to the full scan ability of the nano-LC-QToF-MS system, another ochratoxin (OTB) was detected in the extract of cereal 3. The remaining cereal samples (cereals 1 and 2) were also measured. Like the cereal 3 sample, these samples contained both OTA and OTB (results not shown). The wheat sample found suspect in the FCIA screening, was measured with nano-LC-Q-ToFMS. In agreement with the screening results and LC-QqQMS results, OTA was found in this sample. Furthermore, a blank wheat extract which underwent the immunomagnetic isolation method was injected onto the nano-LC-Q-ToF-MS system. In this extract no ochratoxins were found. The chemical identifications of OTA and OTB were achieved by means of accurate mass, retention time and isotopic pattern (see Tables 1 and 2).

\section{Conclusions}

In this study, a rapid Luminex ${ }^{\circledR}$-based immunoaffinity flow cytometric screening assay with Mab-coated superparamagnetic microbeads was developed. The screening assay proved to be suitable for screening OTA in wheat and cereal samples far below the low ML levels ( 3 and $5 \mathrm{ng} / \mathrm{g}$ ) and at high levels after additional dilutions (e.g. $300 \mathrm{ng} / \mathrm{g}$ ) and no false suspect or false-compliant results were obtained as confirmed by means of an in-house validated reference method based on LC-QqQ-MS. After running the screening assay, all suspect samples were subjected to the newly developed immunoaffinity isolation method for confirmation and identification purposes with nano-LC-QToF-MS using the full scan accurate mass abilities and both OTA and the mycotoxin analogue OTB were identified. The ratio OTA and OTB found in the cereals (10:1) was in agreement with the literature [20]. OTB was not detected routinely by the LC-QqQ-MS reference method due to the preselected specific MRM data acquisition used.

This concept demonstrates the advantages of a miniaturised biospecific-based isolation of mycotoxins to isolate known and unknown or masked analogues which may be overlooked during conventional chemical sample preparation and instrumental analysis. The results presented show the convenience of using the same bioreagents in both the screening and immunoaffinity isolation for MS confirmation and/or identification. For screening food contaminants, MS in MRM mode is widely applied [40-42]. In this concept, nano-LC-Q-ToF in full scan accurate mass mode was used for identification instead. By using nano-LC-QToF, not only the consumption of costly bioreagents decreased significantly, it was also made plausible that unlike targeted MS MRM mode, full scan accurate mass MS is able to detect known and unknown contaminants in affinity purified extracts. Since the extraction procedure is bioactivity-based, both known and unknown emerging food contaminants can be detected which is especially important when more generic or mixtures of antibodies are applied in future experiments.

Table 2 Measured retention time and mass error of OTB in $1 \mathrm{ng} / \mathrm{mL}$ standard and cereal sample

\begin{tabular}{llllll}
\hline $\begin{array}{l}\text { Theoretical } \\
{[\mathrm{M}+\mathrm{H}]^{+}}\end{array}$ & Measurement & $\begin{array}{l}T_{\mathrm{R}} \\
(\mathrm{min})\end{array}$ & $\begin{array}{l}\text { Experimental } \\
{[\mathrm{M}+\mathrm{H}]^{+}}\end{array}$ & $\begin{array}{l}\text { Mass error } \\
(\mathrm{ppm})\end{array}$ & $\begin{array}{l}\text { Elemental composition } \\
{[\mathrm{M}+\mathrm{H}]^{+}}\end{array}$ \\
\hline 370.1291 & Standard & 15.60 & 370.1350 & -16 & $\mathrm{C}_{20} \mathrm{H}_{20} \mathrm{NO}_{6}$ \\
& Sample & 15.60 & 370.1351 & -16 & $\mathrm{C}_{20} \mathrm{H}_{20} \mathrm{NO}_{6}$ \\
\hline
\end{tabular}

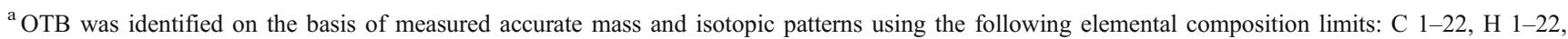
$\mathrm{N}$ 1-5, O 1-9. OTB was the first realistic option within calculated results with reasonable double bond equivalents 
Acknowledgements The authors thank Dr Joerg Stroka (IRMM, Belgium) for kindly providing incurred cereal samples which were used in this research. The Dutch Ministry of Economic Affairs, Agriculture and Innovation is acknowledged for financing this research. Waters is acknowledged for the loan of a Xevo nano-electrospray QToFMS system.

Open Access This article is distributed under the terms of the Creative Commons Attribution Noncommercial License which permits any noncommercial use, distribution, and reproduction in any medium, provided the original author(s) and source are credited.

\section{References}

1. De Saeger S, Sibanda L, Desmet A, Van Peteghem C (2002) A collaborative study to validate novel field immunoassay kits for rapid mycotoxin detection. Int J Food Microbiol 75:135-142

2. Lamberti I, Tanzarella C, Solinas I, Padula C, Mosiello L (2009) An antibody-based microarray assay for the simultaneous detection of aflatoxin B1 and fumonisin B1. Mycotoxin Res 25:193-200

3. Rebe Raz S, Bremer MGEG, Giesbers M, Norde W (2008) Development of a biosensor microarray towards food screening, using imaging surface plasmon resonance. Biosens Bioelectron 24:552-557

4. Faure K, Delaunay N, Alloncle G, Cotte S, Rocca JL (2007) Optimization of in-situ monolithic synthesis for immunopreconcentration in capillary. J Chromatogr A 1149:145-150

5. Visconti A, Pascale M, Centonze G (1999) Determination of ochratoxin A in wine by means of immunoaffinity column cleanup and high-performance liquid chromatography. J Chromatogr A 864:89-101

6. Noba S, Uyama A, Mochizuki N (2009) Determination of ochratoxin A in ready-to-drink coffee by immunoaffinity cleanup and liquid chromatography-tandem mass spectrometry. J Agric Food Chem 57:6036-6040

7. Bonel L, Vidal JC, Duato P, Castillo JR (2010) Ochratoxin A nanostructured electrochemical immunosensors based on polyclonal antibodies and gold nanoparticles coupled to the antigen. Anal Methods 2:335-341

8. Commission Decision (2002)/657/EC of 12 August (2002) implementing Council Directive 96/23/EC concerning the performance of analytical methods and the interpretation of results (2002). Off J Eur Comm., L221, pp 8-28

9. De Keizer W, Bienenmann-Ploum ME, Bergwerff AA, Haasnoot W (2008) Flow cytometric immunoassay for sulfonamides in raw milk. Anal Chim Acta 620:142-149

10. Marchesini GR, Meulenberg E, Haasnoot W, Mizuguchi M, Irth H (2006) Biosensor recognition of thyroid-disrupting chemicals using transport proteins. Anal Chem 78:1107-1114

11. Bovee TFH, Bor G, Becue I, Daamen FEJ, Van Duursen MBM, Lehmann S, Vollmer G, De Maria R, Fox JE, Witters H, Bernhoft S, Schramm KW, Hoogenboom RLAP, Nielen MWF (2009) Interlaboratory comparison of a yeast bioassay for the determination of estrogenic activity in biological samples. Anal Chim Acta 637:265-272

12. Saiyed ZM, Telang SD, Ramchand CN (2003) Application of magnetic techniques in the field of drug discovery and biomedicine. BioMagnetic Research and Technology 1:1-8

13. Dunbar SA (2006) Applications of Luminex ${ }^{\circledR} \mathrm{xMAP}^{\mathrm{TM}}$ technology for rapid, high-throughput multiplexed nucleic acid detection. Clin Chim Acta 363:71-82

14. Liu N, Su P, Gao Z, Zhu M, Yang Z, Pan X, Fang Y, Chao F (2009) Simultaneous detection for three kinds of veterinary drugs: chloram- phenicol, clenbuterol and 17-beta-estradiol by high-throughput suspension array technology. Anal Chim Acta 632:128-134

15. Haasnoot W, Du Pré JG (2007) Luminex-based triplex immunoassay for the simultaneous detection of soy, pea, and soluble wheat proteins in milk powder. J Agric Food Chem 55:3771-3777

16. Kim JS, Taitt CR, Ligler FS, Anderson GP (2010) Multiplexed magnetic microsphere immunoassays for detection of pathogens in foods. Sens Instrum Food Qual Saf 4:73-81

17. Peters J, Bienenmann-Ploum M, De Rijk T, Haasnoot W (2010) Development of a multiplex flow cytometric microsphere immunoassay for mycotoxins and evaluation of its application in feed. Mycotoxin Res. doi:10.1007/s12550-010-0077-0

18. Meimaridou A, Haasnoot W, Noteboom L, Mintzas D, Pulkrabova J, Hajslová J, Nielen MWF (2010) Color encoded microbeadsbased flow cytometric immunoassay for polycyclic aromatic hydrocarbons in food. Anal Chim Acta 672:9-14

19. Ringot D, Chango A, Schneider YJ, Larondelle Y (2006) Toxicokinetics and toxicodynamics of ochratoxin A, an update. Chem -Biol Interact 159:18-46

20. Nielsen KF, Mogensen JM, Johansen M, Larsen TO, Frisvad JC (2009) Review of secondary metabolites and mycotoxins from the Aspergillus niger group. Anal Bioanal Chem 395:1225-1242

21. Ventura M, Vallejos C, Anaya IA, Broto-Puig F, Agut M, Comellas L (2003) Analysis of ochratoxin A in coffee by solidphase cleanup and narrow-bore liquid chromatographyfluorescence detector-mass spectrometry. J Agric Food Chem 51:7564-7567

22. Hernández MJ, García-Moreno MV, Durán E, Guillén D, Barroso CG (2006) Validation of two analytical methods for the determination of ochratoxin A by reversed-phased highperformance liquid chromatography coupled to fluorescence detection in musts and sweet wines from Andalusia. Anal Chim Acta 566:117-121

23. Commission Regulation 1881/2006 of 19 December 2006 setting maximum levels for certain contaminants in foodstuffs (2006). Off J Eur Union, L364, pp 5-24

24. Commission Recommendation 2006/576/EC of 17 August 2006 on the presence of deoxynivalenol, zearalenone, ochratoxin A, T-2 and HT-2 and fumonisins in products intended for animal feeding (2006). Off J Eur Union, L 229, pp 7-9

25. Entwisle AC, Williams AC, Mann PJ, Slack PT, Gilbert J, Burdaspal P, Eklund E, Gardikis J, Hald B, Herry MP, Jørgensen K, Kandler H, Maas R, Martins ML, Patel S, Schuster M, Solfrizzo M, Strassmeir E, Tiebach R, Trogersen T (2000) Liquid chromatographic method with immunoaffinity column cleanup for determination of ochratoxin A in barley: collaborative study. J AOAC Int 83:1377-1386

26. Visconti A, Pascale M, Centonze G (2001) Determination of ochratoxin $\mathrm{A}$ in wine and beer by immunoaffinity column cleanup and liquid chromatographic analysis with fluorometric detection: collaborative study. J AOAC Int 84:1818-1827

27. Chen HX, Busnel JM, Gassner AL, Peltre G, Zhang XX, Girault $\mathrm{HH}$ (2008) Capillary electrophoresis immunoassay using magnetic beads. Electrophoresis 29:3414-3421

28. Wang Z, Liu X, Garduño E, Garduño RA, Li J, Altman E (2009) Application of an immunoaffinity-based preconcentration method for mass spectrometric analysis of the O-chain polysaccharide of Aeromonas salmonicida from in vitro- and in vivo-grown cells. FEMS Microbiol Lett 295:148-155

29. Jonker N, Kretschmer A, Kool J, Fernandez A, Kloos D, Krabbe JG, Lingeman H, Irth H (2009) Online magnetic bead dynamic protein-affinity selection coupled to LC-MS for the screening of pharmacologically active compounds. Anal Chem 81:4263-4270

30. Gao X, Liu W, Yang Q, Liu B, Cai L, Li J, Zhu Z, Xiang M, Yan M (2010) Proteomic profiling of gastric cancer in serum using 
magnetic bead based sample fractionation and MALDI-TOF-MS. Chinese J Clin Oncol 37:933-936

31. Kawamura O, Sato S, Kajii H, Nagayama S, Ohtani K, Chiba J, Ueno Y (1989) A sensitive enzyme-linked immunosorbent assay of ochratoxin A based on monoclonal antibodies. Toxicon 27:887-897

32. Hong C-Y, Chen Y-C (2007) Selective enrichment of ochratoxin A using human serum albumin bound magnetic beads as the concentrating probes for capillary electrophoresis/electrospray ionization-mass spectrometric analysis. J Chromatogr A 1159:250-255

33. Smith PK, Krohn RI, Hermanson GT (1985) Measurement of protein using bicinchoninic acid. Anal Biochem 150:76-85

34. Kim S, Pyo HB, Ko SH, Ah CS, Kim A, Kim WJ (2010) Fabrication of anionic sulfate-functionalized nanoparticles as an immunosensor by protein immobilization. Langmuir 26:7355-7364

35. Desjardins P, Hansen JB, Allen M (2009) Microvolume protein concentration determination using the NanoDrop 2000c spectrophotometer JoVE, issue 33

36. Fountoulakis M, Juranville J-F, Manneberg M (1994) Comparison of the Coomassie brilliant blue, bicinchoninic acid and Lowry quantitation assays, using non-glycosylated and glycosylated proteins. J Biochem Biophys Meth 24:265-274
37. Barna-Vetró I, Solti L, Téren J, Gyöngyösi A, Szabó E, Wölfling A (1996) Sensitive ELISA test for determination of ochratoxin A. J Agric Food Chem 44:4071-4074

38. Radoi A, Dumitru L, Barthelmebs L, Marty JL (2009) Ochratoxin A in some French wines: application of a direct competitive ELISA based on an OTA-HRP conjugate. Anal Lett 42:1187-1202

39. Goryacheva IY, De Saeger S, Nesterenko IS, Eremin SA, Van Peteghem C (2007) Rapid all-in-one three-step immunoassay for non-instrumental detection of ochratoxin A in high-coloured herbs and spices. Talanta 72:1230-1234

40. Krska R, Welzig E, Boudra H (2007) Analysis of Fusarium toxins in feed. Anim Feed Sci Technol 137:241-264

41. Payá P, Anastassiades M, MacK D, Sigalova I, Tasdelen B, Oliva J, Barba A (2007) Analysis of pesticide residues using the quick easy cheap effective rugged and safe (QuEChERS) pesticide multiresidue method in combination with gas and liquid chromatography and tandem mass spectrometric detection. Anal Bioanal Chem 389:1697-1714

42. Di Mavungu JD, Monbaliu S, Scippo ML, Maghuin-Rogister G, Schneider YJ, Larondelle Y, Callebaut A, Robbens J, Van Peteghem C, De Saeger S (2009) LC-MS/MS multi-analyte method for mycotoxin determination in food supplements. Food Addit Contam A 26:885-895 